Bond University

Research Repository

\title{
Hypersensitivity of bladder low threshold, wide dynamic range, afferent fibres following treatment with the chemotherapeutic drugs cyclophosphamide and ifosfamide
}

Mills, Kylie; West, Eleanor; Grundy, Luke; McDermott, Catherine; Sellers, Donna J; Rose'Meyer, Roselyn; Chess-Williams, Russ

Published in:

Archives of Toxicology

DOI:

$10.1007 / \mathrm{s} 00204-020-02773-8$

Licence:

Other

Link to output in Bond University research repository.

Recommended citation(APA):

Mills, K., West, E., Grundy, L., McDermott, C., Sellers, D. J., Rose'Meyer, R., \& Chess-Williams, R. (2020). Hypersensitivity of bladder low threshold, wide dynamic range, afferent fibres following treatment with the chemotherapeutic drugs cyclophosphamide and ifosfamide. Archives of Toxicology, 94(8), 2785-2797. https://doi.org/10.1007/s00204-020-02773-8

\section{General rights}

Copyright and moral rights for the publications made accessible in the public portal are retained by the authors and/or other copyright owners and it is a condition of accessing publications that users recognise and abide by the legal requirements associated with these rights.

For more information, or if you believe that this document breaches copyright, please contact the Bond University research repository coordinator 
Hypersensitivity of bladder low threshold, wide dynamic range, afferent fibres following treatment with the chemotherapeutic drugs cyclophosphamide and ifosfamide.

\section{Kylie Mills ${ }^{1}$, Eleanor West ${ }^{1}$, Luke Grundy ${ }^{2,3}$, Catherine McDermott ${ }^{1}$, Donna Sellers ${ }^{1}$, Roselyn Rose'Myer ${ }^{4}$ and Russ Chess-Williams ${ }^{1}$}

\footnotetext{
${ }^{1}$ Centre for Urology Research, Faculty of Health Sciences \& Medicine, Bond University, Queensland 4229, Australia.

${ }^{2}$ Visceral Pain Research Group, Human Physiology, Centre for Neuroscience, College of Medicine and Public Health, Flinders University, Australia.

${ }^{3}$ Centre for Nutrition and Gastrointestinal Diseases, Discipline of Medicine, University of Adelaide, South Australian Health and Medical Research Institute, Adelaide, Australia ${ }^{3}$ School of Medical Science, Griffith University, QLD4222, Australia.
}

Correspondence: Prof R. Chess-Williams, Centre for Urology Research, Faculty of Health Sciences \& Medicine, Bond University, Queensland 4229, Australia.

Keywords: urothelium, cyclophosphamide, ifosfamide, afferent nerves, bladder function 


\section{SUMMARY}

The cytotoxic drugs cyclophosphamide (CPO) and ifosfamide (IFO) cause toxic urological effects due to the production of urinary metabolites that cause bladder inflammation. This study aimed to identify changes in the bladder afferent system following treatment with these drugs that might explain reported urological adverse effects.

Intravesical pressure and afferent nerve activity were recorded during bladder distension and drug administration in isolated bladders from mice, 24 hours after intraperitoneal treatment with cyclophosphamide $(100 \mathrm{mg} / \mathrm{Kg})$, ifosphamide $(200 \mathrm{mg} / \mathrm{Kg})$ or saline (control).

In isolated bladders, total afferent nerve activity at maximum bladder distension was increased from $182 \pm 13 \mathrm{imp} / \mathrm{sec}$ in control animals, to $230 \pm 14 \mathrm{imp} / \mathrm{sec}$ in CPO-treated $(p<0.05)$ and $226 \pm 17 \mathrm{imp} / \mathrm{sec}$ in IFO-treated $(P<0.001)$ mice. Single fibre analysis revealed the increase resulted from an enhanced activity in low threshold, wide dynamic range fibres $(23.3 \pm 1.9 \mathrm{imp} / \mathrm{sec} /$ fibre in controls to $31.5 \pm 2.5(p<0.01)$ in CPO and $29.9 \pm 2.0$ imp/sec/fibre $(p<0.05)$ in IFO treated). CPO treatment was accompanied by an increase in urinary frequency in vivo, but was not associated with increases in urothelial release of ATP or acetylcholine, bladder compliance or spontaneous muscle activity. Also,CPOtreatment did not affect afferent nerve responses or pressure responses to purinergic, muscarinic or nicotinic agonists.

This is the first report of CPO and IFO-induced changes in specific populations of bladder afferents, namely an increase in low threshold, wide dynamic range fibres. These effects appear to be direct and not secondary to increases in smooth muscle activity or the release of urothelial mediators. 


\section{INTRODUCTION}

Cyclophosphamide (CPO) and ifosfamide, IFO) are commonly used to treat a variety of malignant and non-malignant neoplastic diseases, as well as being used as immunosuppressive agents in bone marrow transplantation and chronic autoimmune disorders (Bergh 2003; Buda et al. 2003; de Jonge et al. 2005; Lawson et al. 2008; Nichols 1995; Sladek 1988). Both CPO and IFO are inactive pro-drugs that must be activated, primarily in the liver to produce the cytotoxic agents, phosphoramide mustard and ifosforamide mustard respectively. During this process other small toxic metabolites such as acrolein are produced that are excreted in the urine and come into direct contact with the bladder urothelium, initiating an inflammatory response (Conklin et al. 2009). The functional effects of this inflammation can manifest as bladder pain, urinary frequency, urgency, dysuria and feelings of incomplete emptying as well as result in life threatening haemorrhagic cystitis (Fukuoka et al. 1991; Korkmaz et al. 2007). As such, these local urological effects are a major limiting factor in the clinical use of CPO and IFO. (Korkmaz et al., 2007; Coggins et al., 1960)

Bladder sensation is mediated by sensory afferents embedded within the bladder wall, acting as tension receptors that respond to bladder stretch. As the adverse urological effects associated with CPO and IFO in humans are sensory in nature, and functional changes usually suggestive of hyperreflexia have been reported in animals treated with CPO or IFO (Andersson et al. 2008; Ito et al. 2008; Juszczak et al. 2009; Kageyama et al. 2008; Macedo et al. 2011; Okinami et al. 2014; Wang et al. 2008b), altered afferent signalling is considered a key component in the development of chemotherapy induced bladder dysfunction. However, few studies have examined the direct effects of CPO or IFO treatment on afferent nerve function and responsiveness.

Dang et al., (2008) reported that CPO treatment causes increased activity of the pelvic nerve afferents during bladder distension (Yu and de Groat 2008), and whole-cell patchclamp recordings of isolated dorsal root ganglion neurones from CPO treated animals demonstrate lower thresholds for spike activation compared to controls (Yoshimura and de Groat 1999). Furthermore, several studies have shown bladder afferent fibres become sensitised by inflammation in-vivo (Habler et al. 1990; Rong et al. 2002; Xu and Gebhart 2008) or simulated inflammation in vitro (Xu \& Gebhart; (2008).

These studies provide evidence that afferent nerve activity is altered after CPO treatment and this is likely a consequence of inflammation. However, it remains to be established if bladder dysfunction following chemotherapy is related to total afferent output or the 
sensitisation of a specific subpopulation of bladder afferent fibres; i.e. low-threshold fibres activated during physiological bladder filling versus high-threshold fibres involved in nociception. Furthermore, mediators such as ATP, acetylcholine (Ach) and prostaglandin E2 (PGE2) are released from the urothelium during bladder filling and influence sensory nerve activity and bladder function (Cockayne et al. 2000; Fry et al. 2007). However their role in chemotherapy induced bladder afferent sensitisation is unknown. In addition, no studies to date have investigated the direct effect of IFO on bladder afferent firing.

\section{MATERIALS AND METHODS}

Animals: Young adult male C57/6B mice (3-5 months old) were treated intraperitoneally $(100 \mu \mathrm{L})$ with saline, CPO $(100 \mathrm{mg} / \mathrm{kg})$ or IFO $(200 \mathrm{mg} / \mathrm{kg})$. Animals were obtained from Griffith University with ethical approval from Griffith University Animals Ethics Committee (MSC/06/13) and the Bond University Ethics committee (Bond University ethics No.RO1762). Animals were euthanised 24 hours after treatment by cervical dislocation in accordance with the guidelines of the National Health and Medical Research Council of Australia.

Afferent Nerve Recording: The opened lower abdomen was secured in a $30 \mathrm{~mL}$ bath continually superfused with Krebs solution (composition in $\mathrm{mM}: \mathrm{NaCl}(188.4 \mathrm{mM}$ ), $\mathrm{NaHCO}_{3}(24.9 \mathrm{mM})$, glucose (11.7 mM), $\mathrm{CaCl}_{2}(1.9 \mathrm{mM}), \mathrm{MgSO}_{4}(1.2 \mathrm{mM})$ and $\mathrm{KH}_{2} \mathrm{PO}_{4}$ $(1.2 \mathrm{mM})$ gassed with $5 \% \mathrm{CO}_{2}$ in oxygen, at a rate of $6 \mathrm{~mL} / \mathrm{min}$ and was maintained at a constant temperature of $35^{\circ} \mathrm{C}$ (Grundy et al. 2018; Chess-Williams et al., 2019). The testes, prostate and surrounding connective tissues were dissected away from the bladder, the ureters were ligated and an intravesical canulae (OD 0.03IN) attached to a syringe pump (Genie, Kent, multi-phaser ${ }^{\mathrm{TM}}$ model NE-1000) allowing bladder distension by infusing isotonic saline $(0.9 \%)$. A two way catheter was inserted into the dome of the bladder to allow measurement of the intravesical pressure via a pressure transducer (DTX ${ }^{\mathrm{TM}}$ plus DT-XX, Becton Dickinson, Singapore) and to allow emptying of its contents via a two-way outflow tap.

Pelvic and hypogastric nerves were dissected into fine multiunit branches as previously described (Grundy et al. 2018), and afferent activity was recorded via a suction electrode (tip diameter 25-50 $\mu \mathrm{m}$ ) attached to a Neurolog headstage (NL100, Digitimer Ltd, UK) connected to an AC pre-amplifier (NL014, Digitimer Ltd). Nerve activity was filtered (NL125, band pass filter, Digitimer Ltd) and passed through a $50 / 60 \mathrm{~Hz}$ electrical noise eliminator (Humbug, Quest Scientific, Canada) to a Micro1401 analogue to digital 
interface (Cambridge Electronic Design, UK) and then visualised on a computer using Spike2 software (version 7.1, Cambridge Electronic Design, UK). Whole nerve multi-fibre and individual unit afferent nerve activity was quantified using the Spike2 software.

Experimental Protocol: The nerve preparation was left to stabilise for $30-60$ minutes with the bladder empty. With the outflow tap closed, the bladder was then distended by filling the bladder with saline $(0.9 \% \mathrm{NaCl})$ at $30 \mu \mathrm{l} / \mathrm{min}$ to a pressure of $40 \mathrm{mmHg}$ before opening the outflow tap allowing the bladder to empty. This was repeated every 10 minutes until a stable pressure and afferent response to distension was observed. The bladder was then distended at $30 \mu \mathrm{l} / \mathrm{min}$ to $20 \mathrm{mmHg}$ and left with the outflow tap closed for 1 hour to allow accommodation of the volume and stabilisation of bladder tone and nerve activity. After the detrusor tone and afferent activity stabilised, pharmacological agents were sequentially added to the bath allowing at least 30 minutes superfusion to wash the tissue between each drug addition to allow intravesical pressure and afferent responses to return to baseline. The following drugs were examined: ATP (1mM) (purinoceptor agonist), aßmethylene ATP $(10 \mu \mathrm{M})(\mathrm{P} 2 \mathrm{X}$ purinoceptor agonist), ACh $(1 \mu \mathrm{M})$ (muscarinic and nicotinic receptor agonist), carbachol $(10 \mu \mathrm{M})$ (muscarinic receptor agonist), DMPP $(10 \mu \mathrm{M})$ (nicotinic receptor agonist).

In separate experiments the responses to ATP $(1 \mu \mathrm{M})$, aßmethylene ATP $(10 \mu \mathrm{M})$, carbachol $(10 \mu \mathrm{M})$ and DMPP $(10 \mu \mathrm{M})$ were repeated in the absence and presence of nifedipine $(1 \mu \mathrm{M})$ to block smooth muscle contraction. These experiments were performed in control and CPO $(100 \mathrm{mg} / \mathrm{kg})$ treated mice only. The pressure and nerve responses remaining in the presence of nifedipine $(1 \mu \mathrm{M})$ were expressed as a percentage of the response in the absence of nifedipine.

Mediator Release: During collection of luminal and serosal samples for the assay of mediators, tissue superfusion was stopped and tissues were maintained in the $8 \mathrm{~mL}$ bath of Krebs solution by gassing with $5 \% \mathrm{CO}_{2}$ in oxygen. Mediator release was measured in luminal contents following distention to $20 \mathrm{mmHg}$ with saline (stretch). A sample of the Krebs in the bath in contact with the bladder serosa was also collected and stored at $20^{\circ} \mathrm{C}$ for later analysis. Samples were collected onto dry-ice and assayed for ATP (Molecular Probes $\AA^{\circledR}$ A22066), Ach (Molecular Probes $®$ A12217) and PGE2 (Cayman’s PGE2 EIA Kit) using commercially available kits.

Afferent nerve activity: Multi-unit and single-unit nerve activity was quantified using Spike2 software. Baseline afferent activity was obtained by averaging the discharge in the 100 second period prior to the distension. The afferent nerve response during 
bladder distension was calculated by measuring the afferent activity (imp/sec) at each intravesical pressure increment up to $40 \mathrm{mmHg}$.

Spontaneous Contractions: During bladder filling phasic intravesical pressure increases were observed and these were associated with phasic changes in afferent nerve activity. The frequency and amplitude of spontaneous contractions during filling were measured during the 200 s preceding the intravesical pressure reaching $15 \mathrm{mmHg}$.

Voiding Analysis: To determine if CPO treatment altered voiding behaviour, voiding analysis was performed on the mice before and after treatment, as previously described (West et al. 2018). All voiding pattern analysis was performed at the beginning the light cycle. Mice were housed individually for 4 hours in cages lined with Filtech® Haless Filter Paper \#225 with free access to food and water. Urine spots on the filter paper were detected using a Molecular Imager ChemiDoc XRS ultraviolet transilluminator (\#720BR1293 BioRad, California USA). They were photographed, digitised, and analysed using Image $\mathrm{J}$ software.

Statistical Analysis: Results are expressed as mean \pm standard error of the mean (SEM). Data were analysed using a Student t-test or one-way ANOVA with Dunnett or Tukey multiple comparisons test as appropriate, using Graphpad InStat (version 3.06) software (SanDiego, CA). Comparisons of whole response curves of control and treated groups were performed using two-way ANOVA with Bonferroni post-test. Significance levels were defined as $p<0.05\left(^{*}\right), p<0.01\left(^{* *}\right)$ and $\left.p<0.001{ }^{* * *}\right)$.

\section{RESULTS}

Before treatment, there was no significant difference in age or weight between animal groups, but both cytotoxic drug treatments resulted in weight loss after 24 hours (3.1 \pm $0.3 \%, p<0.01$ for CPO and $3.4 \pm 0.5 \%, p<0.001$ for IFO). Average bladder volumes at maximum distension $(40 \mathrm{mmHg})$ were not different between the three groups.

\section{Cyclophosphamide and Ifosphamide sensitise mechanosensitive bladder afferents}

In order to determine if CPO induced bladder dysfunction is a consequence of altered bladder afferent mechanosensitivity, bladder afferent firing was recorded in response to bladder distension (Fig 1A\&B). As bladder volume increased, there was a corresponding increase in intravesical pressure and subsequent increase in bladder afferent nerve 
activity. Bladder filling typically included an initial compliant phase, $(0-15 \mathrm{mmHg})$ which is characterised by a large increase in bladder volume for a relatively small increase in intravesical pressure that is accompanied by a significant increase in afferent nerve activity. This phase was followed by a steep increase in pressure which was accompanied by a smaller increase in afferent nerve activity. The pattern of filling was highly reproducible and occurred in all bladders in all treatment groups.

Treatment with CPO $(100 \mathrm{mg} / \mathrm{kg}, \mathrm{n}=10)$ or IFO $(200 \mathrm{mg} / \mathrm{kg}, \mathrm{n}=11)$ did not affect bladder compliance (Fig 1C), but did significantly enhanced total bladder afferent activity to distension compared to control mice ( $n=11$, Fig 1D). There was no difference between the CPO and IFO treatment groups. The single units were identified in each preparation and the average number of distinct nerve fibres was not significantly different between treatment groups. The single fibres were also classified based on their activation threshold and the number of both low and high threshold fibres was similar between groups. Low threshold fibres were more numerous than high threshold fibres in all treatment groups (Fig 1E). Accordingly, low threshold fibres made up $59.8 \pm 8.8 \%$ of the total fibre population in control bladders and while not significant, treatment with CPO or IFO showed a trend towards an increasing population of low threshold fibres to $76.5 \pm 7.1 \%$ and $75.8 \pm 6.3 \%$ respectively.

Using single unit analysis to further characterise these differences revealed that the overall increases in afferent firing was due to an increase in the mechanosensitivity of individual units (Fig 1F). Since the increase in afferent firing was not accompanied by any change in bladder compliance during distensions, bladder dysfunction following CPO is likely mediated by aberrant afferent firing, not through dysregulation of muscle function. Interestingly, the enhanced mechanosensitivity in CPO and IFO treated mice appears to be mediated by afferents activated at lower distension pressures $(\leq 15 \mathrm{mmHg})$ as the percentage difference in firing is maintained, but not further enhanced at higher distension pressures.

Phasic contractions: During bladder distension, phasic intravesical pressure changes were observed in some bladders (Fig 2), the numbers developing this activity being similar in all groups (8/11 control, 7/10 CPO and 7/11 IFO). The frequency and amplitude of these phasic contractions were also similar in all experimental groups (Fig 2C and 2D). Interestingly, the phasic contractile activity was associated with very obvious phasic changes in afferent nerve activity (Fig $2 \mathrm{~B}$ ), but the relationship between phasic pressure change and nerve activity was unchanged by drug pretreatments, with the nerve activity 
change per $\mathrm{mmHg}$ pressure change being similar in all groups $(8.6 \pm 6.1,13.4 \pm 6.7$ and $8.7 \pm 4.3 \mathrm{imp} / \mathrm{sec} / \mathrm{mmHg}$ in control, CPO and IFO respectively). The spontaneous detrusor contractions persisted in the presence of tetrodotoxin $(1 \mu \mathrm{M})$ which abolished the nerve activity.

Mediator Release: Samples taken from the lumen of distended bladders and from the serosal solution surrounding the bladder were analysed for ATP and acetylcholine (Ach) content (Fig 3). Each mediator concentration was then normalised to volume to obtain the total amount released. More than 10 times the amount of ATP (pmoles) was released from the serosa than the lumen $(p<0.001)$. Similarly, the total amount of Ach was significantly higher $(30$-fold) in serosal samples than in luminal samples $(p<0.01)$. Treatment with CPO $(100 \mathrm{mg} / \mathrm{kg})$ did not affect the total amount of ATP or ACh released from either the lumen or the serosa of the mouse bladder (Fig 3). However, treatment with IFO $(200 \mathrm{mg} / \mathrm{kg})$ caused a reduction in the luminal ATP levels by $50 \%(p<0.05)$, but had no significant effect on ACh levels in either luminal or serosal samples.

Single unit analysis ; To further characterise the single-unit subtypes responsible for CPO and IFO induced afferent hypersensitivity, individual fibres were classified based on their activation threshold (Fig 4). Low threshold fibres had a greater firing rate at maximum distension compared to high threshold fibres $(p<0.01)$. A significant enhancement in the mechanosensitivity of low threshold single units following treatment was observed with CPO and IFO ( $p<0.05)$. The activity of high threshold units, however, was unchanged after treatment with CPO or IFO.

Amongst low threshold fibres, two distinct response patterns were observed (Fig 4). In the first pattern, low threshold afferents show a gradual increase in afferent excitability up to maximum distension, exhibiting a wide dynamic range (WDR). The second group demonstrated a narrower dynamic range where firing rate plateaued, or even decreased in activity after $\approx 15 \mathrm{mmHg}$. These traditional low-threshold fibres were more numerous than WDR fibres in all animal groups. Following treatment with CPO or IFO (all groups $\geq 6$ animals), WDR fibres exhibited significantly enhanced mechanosensitivity $(n=17,20$ and 16 fibres for control, CPO and IFO), whilst treatments with either CPO or IFO had no effect on the activity of fibres with a narrow dynamic range $(n=35,28$ and 28 fibres in control, CPO and IFO, Fig 4). These data indicate that the effects of CFO and IFO on mechanosensitivity and the subsequent changes in bladder voiding parameters are almost exclusively mediated by low threshold fibres with a wide dynamic range. 
Response to Pharmacological Agents: Initially the bladder was filled to $20 \mathrm{mmHg}$ and left until pressure and nerve activity were stable in order to quantify the responses to various agonists. Compliance of the bladder was unchanged by treatment with CPO $(100 \mathrm{mg} / \mathrm{kg})$ or IFO $(200 \mathrm{mg} / \mathrm{kg})$, but total nerve activity was increased at $20 \mathrm{mmHg}$ in both CPO and IFO treated animals, however the nerve activity adapted over time to be similar to the activity in control animals. Control, CPO and IFO-treated bladders stabilised to similar intravesical pressures $(6.01 \pm 0.71 \mathrm{mmHg}, 6.96 \pm 0.65 \mathrm{mmHg}$ and $7.00 \pm 1.62 \mathrm{mmHg}$ respectively) and nerve firing rates $(32.0 \pm 16.1 \mathrm{imp} / \mathrm{sec}, 43.5 \pm 23.2 \mathrm{imp} / \mathrm{sec}$ and $24.2 \pm 7.62 \mathrm{imp} / \mathrm{sec}$ respectively) after approximately 30 minutes. The effects of pharmacological agents were then determined from this stable tension and afferent activity.

In control preparations, extraluminal application of the purinergic agonists ATP (1mM) and $\alpha \beta m A T P(10 \mu \mathrm{M})$ and the cholinergic agonists ACh $(1 \mu \mathrm{M})$ and carbachol $(10 \mu \mathrm{M})$ elicited significant rises in intravesical pressure and afferent nerve activity (Fig 5). DMPP $(10 \mu \mathrm{M})$, a nicotinic agonist, produced a large increase in nerve activity but only a small increase in intravesical pressure that was small compared to the other agonists. Treatment with CPO or IFO treatment did not significantly affect either pressure responses or afferent nerve responses to any of the agonists (Fig 5).

Responses to the agonists were also examined in the presence of nifedipine (1uM) in bladders from control and CPO treated animals. In control bladders, nifedipine $(1 \mu \mathrm{M})$ significantly reduced the intravesical pressure responses to ATP $(1 \mathrm{mM}), \alpha \beta m A T P(10 \mu \mathrm{M})$ and carbachol $(10 \mu \mathrm{M})$ (Fig 6). Nifedipine reduced responses to DMPP from $0.37 \pm 0.27 \mathrm{mmHg}$ to $0.07 \pm 0.05 \mathrm{mmHg}$, but due to the small magnitude of the responses these changes were not statistically significant. In contrast to the significant reduction in muscle contraction to these agents, nifedipine had less effect on nerve responses and only reduced the responses to carbachol $(10 \mathrm{nM})(\mathrm{p}<0.05)$.

Nifedipine reduced intravesical pressure responses to a similar extent in both control and CPO treated bladders. The reductions of pressure responses to the agonists by nifedipine were similar in bladders from control and CPO treated animals (ATP, 83 $\pm 8 \%$ vs $72 \pm 8 \%$; aßmATP $75 \pm 5 \%$ vs $78 \pm 8 \%$; carbachol $80 \pm 1 \%$ vs $82 \pm 2 \%$; DMPP $94 \pm 5 \%$ vs $98 \pm 1 \%$ respectively). In these bladders from CPO treated animals, nerve activity again was less affected than pressure responses by nifedipine $(1 \mu \mathrm{M})$, and reductions in responses were again similar for bladders from control and treated animals for ATP ( $37 \pm 14 \%$ vs $16 \pm 28 \%)$; a $3 \mathrm{mATP}(18 \pm 13 \%$ vs $38 \pm 5 \%)$; carbachol $(49 \pm 10 \%$ vs $54 \pm 10 \%)$. 
Voiding function: To measure bladder function in vivo, the voiding patterns of control and CPO treated mice were investigated. During the 4 hour voiding analysis period, urine production was similar in the control and CPO treated animals, but the total number of voids was significantly greater $(P<0.05)$ in the $C P O$-treated animals $(66.9 \pm 17.8)$ than in control animals (24.8 \pm 7.2$)$.

\section{DISCUSSION}

CPO is used in patients to treat a number of conditions, but urinary adverse effects are common due to metabolites such as acrolein and chloroacetaldehyde (CAA), which irritate the bladder (Mills et al., 2019). For this reason, the drug is also commonly used in animals as a model of bladder inflammation. Acrolein and CAA are thought to influence bladder function after delivery in the urine, however urothelial mediator release was unchanged suggesting urothelial function, and possibly barrier function, are normal. An alternative possibility is that the metabolites exert their actions on bladder structures following delivery in the blood via capillaries in the suburothelium putting the toxins in close proximity with the sensory nerves.

Several studies have used CPO or IFO to treat cancer in murine models and the reported doses range between $30 \mathrm{mg} / \mathrm{kg}$ - $200 \mathrm{mg} / \mathrm{kg}$ intraperitoneally for CPO (Harnack et al. 2011; Kusnierczyk et al. 1999; Ma et al. 2011) and 60 - 350 mg/kg intraperitoneally for IFO (Brucker and Sieg 1999; Silbermann et al. 1990; Wang et al. 2008a; Yamada et al. 2009). For this study, a CPO dose of $100 \mathrm{mg} / \mathrm{kg}$ and an IFO dose of $200 \mathrm{mg} / \mathrm{kg}$ were chosen which fall within the doses used for cancer treatments in mice.

Treatment of mice with CPO or IFO did not affect bladder compliance, but did enhance total afferent nerve firing during bladder distension. Although activity was enhanced at maximum distension, a greater enhancement was observed at lower intravesical pressures of around $15 \mathrm{mmHg}$. An intravesical pressure of $15 \mathrm{mmHg}$ corresponds to the approximate micturition threshold in mice (Igawa et al. 2004). Therefore, it appears the effects of CPO and IFO on afferent activity are most apparent during typical physiological filling. An increase in afferent activity by $\mathrm{CPO}$ in the rat has been reported previously $(\mathrm{Yu}$ and de Groat 2008), but in that study a marked variability was found between the afferent responses that was thought to be due to variation in the number of fibres present in the 
afferent branch during recording. An increase in firing of DRG neurones from CPO treated rats also suggested this mechanism (Dang et al. 2008; Yoshimura and de Groat 1999). Accordingly, the present study investigated directly whether increased afferent activity after CPO or IFO treatment is due to increased firing of individual fibres or rather an overall increase in fibre density. The number of fibres in our study was similar in all groups and the enhanced nerve activity after CPO and after IFO was shown to occur in individual fibres.

A number of classification systems exist for afferent fibres. One is based on whether the fibres become active at low $(<15 \mathrm{mmHg})$ or high $(>15 \mathrm{mmHg})$ intravesical pressures (Daly et al. 2007; Rong et al. 2002; Shea et al. 2000). Stretch sensitive bladder afferent nerves have also been classified based on their functional response patterns where fibres respond over a wide dynamic range (WDR) increasing to maximum stretch, or they may only respond over a more limited narrower dynamic range and reach peak activity at lower than maximum stretch. These types have also been referred to as encoding and non-encoding fibres respectively (Shea et al., 2000). Both response patterns have been shown previously in mice (Xu and Gebhart 2008) with the narrower range fibres being more common. The present study found that $60-75 \%$ of all fibres were low threshold, a figure similar to previous reports (Daly et al., 2007, Rong et al., 2002).

All high threshold fibres demonstrated a firing pattern with activity that increased continuously up to maximum distension as reported by Xu \& Gebhart (2008), while both firing patterns were observed in the low-threshold nerves with the narrower dynamic range fibres being more common. Treatment with CPO or IFO enhanced the activity of the low threshold fibres, but not the high threshold fibres Exposure to an inflammatory medium in vitro has been shown to reduce the response threshold of high threshold fibres to a level comparable to that of the low threshold fibres (Xu \& Gebhart (2008). Interestingly, the response pattern of some of the narrow range low threshold fibres also changed after exposure to the inflammatory environment with fibres responding up to maximum stretch. In the present study separate mice were treated with saline, CPO or IFO and accordingly it was not possible to determine whether the drugs lowered the activation threshold of high threshold fibres. However, the percentage of low threshold fibres appeared to be increasing after treatment, which may suggest that some narrow dynamic range fibres may have been altered by CPO or IFO.

Typically, low threshold fibres are thought to contribute to normal micturition reflexes and high threshold fibres to painful sensations. However, given that low threshold fibres can 
encode stretch stimuli into the pain/noxious range $(>15 \mathrm{mmHg})$ and can sensitise, it appears possible they may also contribute to painful sensations. Accordingly, the increased activity of low threshold fibres after CPO or IFO treatment may explain the bladder hyperactivity (urgency, frequency), abnormal sensations (residual volume) as well as the painful sensations experienced by patients following treatment with these cytotoxic drugs. Furthermore, high threshold fibres becoming active at lower thresholds could also explain abnormal sensations of fullness and pain at lower bladder volumes.

The mechanism of the CPO/IFO induced bladder afferent nerve hypersensitivity is unknown. Various mediators released by the urothelium can activate and sensitise afferent nerves and may possibly sensitise afferent nerves after CPO/IFO treatment. It was observed that mediator levels were higher at the serosal surface than the luminal surface, confirming a previous study using Ussing chambers (Fergusson et al., 1997). The detrusor muscle can release a small amount of ATP when stretched but the greatest release comes from the cells of the mucosa (Cheng et al., 2011). It is likely that the lower levels at the luminal surface may reflect the barrier function of the urothelium which could limit diffusion into the lumen. A previous study found enhanced ATP release following multiple, high doses of CPO (Smith et al., 2005), but with the single lower dose of CPO used in the present study, changes in urothelial mediator release were not observed. It was not possible to measure mediator release at the suburothelium, and thus indirect actions via mediators cannot be completely excluded, but it would seem unlikely since mediator levels were unchanged at the luminal and serosal bladder surfaces following CPO and IFO treatment.

Interestingly in DRG from CPO treated rats, P2X3 receptors have been found to be upregulated and a greater number of neurones responded to purinergic agonists (Dang et al. 2008), suggesting normal levels of ATP release could still possibly produce enhanced nerve activity. However our study showed that nerve and pressure responses to purinergic agonists, both ATP and aßmATP were similar in all experimental groups. Also, when nifedipine was used to depress smooth muscle contractions and isolate the nerve responses, these purinergic afferent responses were not altered following CPO or IFO treatment. This again indicates that changes in mediator release or action do not explain the afferent hypersensitivity observed in the current study.

Although nerve activity was increased at $20 \mathrm{mmHg}$ after CPO or IFO treatment, the firing rate in both treatment groups was able to accommodate over time to a level comparable to controls. This gave a fairly consistent baseline firing rate from which responses to 
various agonists could be assessed. Both the purinergic agonists (ATP, aßmATP) increased intravesical pressure and afferent nerve activity, which is not surprising given that bladder smooth muscle and afferent nerves express purinergic receptors and activation causes neurone depolarisation triggering action potentials (Dang et al. 2008). The effect of nifedipine on purinergic responses was the same in bladders from control and CPO-treated animals, reducing both the pressure and nerve responses in a similar fashion. Accordingly, the contribution of muscle tone to purinergic afferent nerve responses is the same after $\mathrm{CPO}$ treatment.

Muscarinic nerve responses to carbachol (and Ach) were also associated with an increase in intravesical pressure, both responses increasing and recovering to baseline at a similar rate. Nifedipine depressed pressure responses to carbachol, but this was accompanied by reduced nerve responses, indicating that unlike purinergic responses, at least a part of the muscarinic response is mediated indirectly via changes in smooth muscle tone. The total nerve activity is a combination of mechanical stimulation due to muscle contraction plus direct nerve stimulation by the agonists. This can be seen with nerve responses to carbachol which were greatly reduced as nifedipine reduced the contractile response. However, for the purinergic agonists and nicotine the greatest effects are on the nerve itself and thus nifedipine has less of an influence on nerve responses to these agonist. $\mathrm{Yu}$ and Groat (2010) also reported that intravesical muscarinic agonists increase afferent nerve activity during bladder distention but not in the absence of bladder distention (Yu and de Groat 2010), whilst Daly et al. (2010) found that muscarinic receptor stimulation during bladder distension significantly inhibited afferent firing. Accordingly, the effects of muscarinic receptor stimulation on afferent firing are still unclear. To add to the confusion, muscarinic receptors are present on urothelial cells and can cause the release of excitatory mediators such as ATP (Nile and Gillespie 2012; Yokoyama et al. 2011) and thus elicit indirect activation of the afferent nerves. In terms of muscle tone contributing to afferent nerve response, both control and CPO groups demonstrated similar reductions in pressure and nerve responses after nifedipine, again suggesting that in CPO-treated bladders the relationship between muscle tone and nerve responses is unchanged.

In contrast, the direct effects of nicotinic receptor stimulation with DMPP were very clear. DMPP had almost no effect on pressure, but elicited large increases in nerve activity in the absence and in the presence of nifedipine. Nicotinic receptors particularly the $\alpha 3-$ containing subtype are expressed in bladder sensory nerves in mice (Nandigama et al. 2013) and nicotinic afferent nerve responses have been reported previously (Masuda et 
al. 2006; Beckel \& Birder, 2012). However their function in CPO-induced inflammatory responses has never been investigated. In the present study, CPO or IFO treatment did not significantly affect any of the responses to the various agonists, indicating that the enhanced nerve activity during distention in treated animals was not due to an increase in nerve sensitivity to purinergic or cholinergic stimulation.

Spontaneous phasic pressure changes were observed in some bladders in all experimental groups and were associated with phasic nerve activity which mimicked the muscle activity. The neurotoxin tetrodotoxin abolished nerve responses without affecting phasic muscle contractions, further demonstrating the influence of muscle tension on afferent nerve activity (McCarthy et al. 2009; Zagorodnyuk et al. 2007). The results of the present study demonstrated that treatment with CPO or IFO did not significantly affect the frequency or amplitude of spontaneous contractions during filling or accommodation of the bladder. It has been suggested that spontaneous contractions play a significant role in generating afferent activity (Heppner et al., 2016) and the possibility that the relationship between phasic contractions and nerve activity may have been altered following treatment was investigated. The increase in nerve activity when expressed as the increase in impulses for each $\mathrm{mmHg}$ rise in pressure during phasic contractions was unchanged following CPO or IFO treatment, indicating that the relationship was not affected by these drug treatments. Thus neither spontaneous contractions nor the nerve activity associated with this phasic activity were altered by drug pretreatments.

When the voiding patterns of animals was examined over a 4 hour period, there was an increase in voiding frequency following CPO treatment without any change in the volume of urine produced. Thus the increased bladder afferent activity in these animals was associated with increased micturition supporting the hypothesise that the symptoms of urgency and frequency observed in patients following CPO treatment result from an afferent nerve sensitisation with exaggerated afferent input to the spinal cord triggering the micturition reflex at lower distension pressures.

In conclusion, CPO and IFO treatment enhanced total nerve activity in the mouse bladder during graded distensions and this was due to enhanced activity of the low threshold wide dynamic range fibres. In addition, an increased ability of low threshold fibres to respond into the noxious range of bladder pressures may also be involved in the enhanced activity. This is the first study to report the effects of CPO and IFO on low and high threshold pelvic sensory nerves in the mouse bladder. The increased afferent 
activity does not appear to be due to enhanced responses to urothelial ATP or acetylcholine but rather appears to be due to a direct sensitisation of the nerves to distension.

\section{Acknowledgements}

This work was supported by a grant from Cancer Council Queensland. Kylie Mills received a Bond University Postgraduate Research Scholarship.

Conflict of Interest Statement: The authors declare that they have no conflict of interest. 
This is a post-peer-review, pre-copyedit version of an article published in Archives of Toxicology.

The final authenticated version is available online at: http://dx.doi.org/10.1007/s00204-020-02773-8

\section{REFERENCES}

Andersson M, Tobin, G, Giglio D (2008) Cholinergic nitric oxide release from the urinary bladder mucosa in cyclophosphamide-induced cystitis of the anaesthetized rat. Br J Pharmacol 153(7):1438-44

Aronsson P, Johnsson M, Vesela R, Winder M, Tobin G (2012) Adenosine receptor antagonism suppresses functional and histological inflammatory changes in the rat urinary bladder. (Translated from eng) Auton Neurosci 171(1-2):49-57

Beckel J M, Birder L A (2012) Differential expression and function of nicotinic acetylcholine receptors in the urinary bladder epithelium of the rat. J Physiol 590(6):1465-80

Bergh J (2003) Best use of adjuvant systemic therapies II, chemotherapy aspects: dose of chemotherapy-cytotoxicity, duration and responsiveness. Breast 12(6):529-37

Brucker C, Sieg P (1999) Effect of combined carboplatin and ifosfamide with local hyperthermia on human mouth carcinoma in the animal model. Mund Kiefer Gesichtschir 3(Suppl 1):S144-6

Buda A, Dell'Anna T, Signorelli M, Mangioni C (2003) Role of ifosfamide in cervical cancer: an overview. Oncology 65 (Suppl 2):63-6

Cheng Y, Mansfield KJ, Sandow SL, Sadananda P, Burcher E (2011) Porcine bladder urothelial, myofibroblast and detrusor muscle cells: characterisation and ATP release. Frontiers in Pharmacology 2: 1-16

Cockayne D A, Hamilton SG, Zhu QM, Dunn PM, Zhong Y, Novakovic S, Malmberg AB, Cain G, Berson A, Kassotakis L, Hedley L, Lachnit WG, Burnstock G, McMahon SB, Ford AP (2000) Urinary bladder hyporeflexia and reduced pain-related behaviour in P2X3deficient mice. Nature 407(6807):1011-5

Coggins PR, Ravdin RG, \& Eisman SH (1960) Clinical evaluation of a new alkylating agent: cytoxan (cyclophosphamide). (Translated from eng) Cancer 13:1254-1260.

Conklin DJ, Haberzettl P, Lesgards JF, Prough RA, Srivastava S, Bhatnagar A (2009) Increased sensitivity of glutathione S-transferase P-null mice to cyclophosphamide-induced urinary bladder toxicity. J Pharmacol Exp Ther 331(2):456-69

Daly D, Rong W, Chess-Williams R, Chapple C, Grundy D (2007) Bladder afferent sensitivity in wild-type and TRPV1 knockout mice. J Physiol 583(2):663-74

Daly DM, Chess-Williams R, Chapple C, Grundy D (2010) The inhibitory role of acetylcholine and muscarinic receptors in bladder afferent activity. Eur Urol 58(1):22-8

Dang K, Lamb K, Cohen M, Bielefeldt K, Gebhart GF (2008) Cyclophosphamide-induced bladder inflammation sensitizes and enhances P2X receptor function in rat bladder sensory neurons. J Neurophysiol 99(1):49-59

Deberry JJ, Schwartz ES, \& Davis BM (2014) TRPA1 mediates bladder hyperalgesia in a mouse model of cystitis. Pain 155(7):1280-7

de Jonge ME, Huitema AD, Rodenhuis S, Beijnen JH (2005) Clinical pharmacokinetics of cyclophosphamide. Clin Pharmacokinet 44(11):1135-64

Ferguson DR, Kennedy I \& Burton TJ: 1997 'ATP is released from rabbit urinary bladder epithelial cells by hydrostatic pressure changes - a possible sensory mechanism?' $J$ Physiol 1997; 505, pp 503-511.

Fry $\mathrm{CH}$, Sui GP, Kanai AJ, Wu C (2007) The function of suburothelial myofibroblasts in the bladder. Neurourol Urodyn 26(6):914-9

Fukuoka M, Negoro S, Masuda N, Furuse K, Kawahara M, Kodama N, Ikegami H, Nakamura S, Nishio H, Ohnoshi T (19910 Placebo-controlled double-blind comparative study on the preventive efficacy of mesna against ifosfamide-induced urinary disorders. J Cancer Res Clin Oncol 117(5):473-8

Grundy L, Chess-Williams R, Brierley SM, Mills K, Moore KH, Mansfield K, Rose'Meyer R, Sellers DJ, Grundy D (2018) NKA enhances bladder-afferent mechanosensitivity via urothelial and detrusor activation. Am Journal Physiol- Renal Physiol 315(4):F1174F1185

Chess-Williams R, Sellers DJ, Brierley SM, Grundy D, Grundy L (2019) Purinergic receptor 
This is a post-peer-review, pre-copyedit version of an article published in Archives of Toxicology.

The final authenticated version is available online at: http://dx.doi.org/10.1007/s00204-020-02773-8

mediated calcium signalling in urothelial cells. Sci Reports 9: Article number 16101

Habler HJ, Janig W, Koltzenburg M (1990) Activation of unmyelinated afferent fibres by mechanical stimuli and inflammation of the urinary bladder in the cat. J Physiology 425:545-62

Harnack U, Eckert K, Pecher G (2011) Beta-(1-3),(1-6)-D-glucan enhances the effect of lowdose cyclophosphamide treatment on A20 lymphoma in mice. Anticancer Res 31(4):1169-72

Heppner TJ, Tykocki NR, Hills-Eubanks D Nelson MT (2016) Transient contractions of urinary bladder smooth muscle are drivers of afferent nerve activity during filling. J Gen Physiology 147(4):323-335

Igawa $\mathrm{Y}$, Zhang $\mathrm{X}$, Nishizawa $\mathrm{O}$, Umeda $\mathrm{M}$, Iwata $\mathrm{A}$, Taketo MM, Manabe $\mathrm{T}$, Matsui $\mathrm{M}$, Andersson KE (2004) Cystometric findings in mice lacking muscarinic M2 or M3 receptors. J Urol 172(6, part 1):2460-4

Ito K, Iwami A, Katsura H, Ikeda M (2008) Therapeutic effects of the putative P2X3/P2X2/3 antagonist A-317491 on cyclophosphamide-induced cystitis in rats. Naunyn-Schmiedeb Arch Pharmacol 377(4-6):483-90

Juszczak K., Ziomber A, Wyczolkowski M, Thor PJ. (2009) Urodynamic effects of the bladder C-fiber afferent activity modulation in chronic model of overactive bladder in rats. $J$ Physiol Pharmacol : an official journal of the Polish Physiological Society 60(4):85-91

Kageyama A, Fujino T, Taki Y, Kato Y, Nozawa Y, Ito Y, Yamada S (2008) Alteration of muscarinic and purinergic receptors in urinary bladder of rats with cyclophosphamideinduced interstitial cystitis. Neurosci letts 436(1):81-4

Korkmaz A, Topal T, \& Oter S (2007) Pathophysiological aspects of cyclophosphamide and ifosfamide induced hemorrhagic cystitis; implication of reactive oxygen and nitrogen species as well as PARP activation. (Translated from eng) Cell Biol Toxicol 23(5):303312

Kusnierczyk H, Pajtasz-Piasecka E, Radzikowski C (1999) Synergistic antitumour effects of chemo-immunotherapy with an oxazaphosphorine drug and IL-2-secreting cells in a mouse colon cancer model. Med Oncol 16(4):267-78

Lawson M, Vasilaras A, De Vries A, Mactaggart P, Nicol D (2008) Urological implications of cyclophosphamide and ifosfamide. (Translated from eng) Scand J Urol Nephrol 42(4):309-317.

Lee HY, Bardini M, Burnstock G (2000) Distribution of P2X receptors in the urinary bladder and the ureter of the rat. J Urol 163:2002-2007

Ma X, Liu Z, Yang X, Gao Q, Zhu S, Qi, C, Liu K, Zhang B, Han D, Wang F, Tian J (2011) Dualmodality monitoring of tumor response to cyclophosphamide therapy in mice with bioluminescence imaging and small-animal positron emission tomography. Mol Imaging 10(4):278-83

Macedo FY, Baltazar F, Almeida PR, Tavora F, Ferreira FV, Schmitt FC, Brito GA, Ribeiro RA (2008) Cyclooxygenase-2 expression on ifosfamide-induced hemorrhagic cystitis in rats. J Cancer Res Clin Oncol 134(1):19-27

Masuda H, Hayashi Y, Chancellor MB, Kihara K, de Groat WC, de Miguel F, Yoshimura N (2006) Roles of peripheral and central nicotinic receptors in the micturition reflex in rats. $\mathrm{J}$ Urol 176(1):374-9

McCarthy CJ, Zabbarova IV, Brumovsky PR, Roppolo JR, Gebhart GF, Kanai AJ (2009) Spontaneous contractions evoke afferent nerve firing in mouse bladders with detrusor overactivity. J Urol 181(3):1459-66

Mills KA, Chess-Williams R, McDermott C (2019) Novel insights into the mechanism of cyclophosphamide-induced bladder toxicity: chloroacetaldehyde's contribution to urothelial dysfunction in vitro. Arch Toxicol 93(11):3291-3303

Nandigama R, Ibanez-Tallon I, Lips KS, Schwantes U, Kummer W, Bschleipfer T (2013) Expression of nicotinic acetylcholine receptor subunit mRNA in mouse bladder afferent neurons. Neurosci 229:27-35 
Nichols CR (1995) The role of ifosfamide in germ cell tumors and small cell lung cancer. Semin Oncol 22(3 Suppl 7):13-7

Nile CJ, Gillespie $\mathrm{JI}$ (2012) Interactions between cholinergic and prostaglandin signaling elements in the urothelium: role for muscarinic type 2 receptors. Urol 79(1):240 e17-23

Rong W, Spyer KM, Burnstock G (2002) Activation and sensitisation of low and high threshold afferent fibres mediated by $\mathrm{P} 2 \mathrm{X}$ receptors in the mouse urinary bladder. J Physiol 541(2):591-600

Shea VK, Cai R, Crepps B, Mason JL, Perl ER (2000) Sensory fibers of the pelvic nerve innervating the Rat's urinary bladder. J Neurophysiol 84(4):1924-33

Silbermann MH, vd Vecht B, Stoter G, Nooter K, Verweij J (1990) Combination therapy of ACNU and ifosfamide in tumor bearing mice with M2661 breast cancer, B16 malignant melanoma or C38 colon cancer. Eur J Cancer 26(3):321-5

Sladek NE, Priest J, Doeden D, Mirocha CJ, Pathre S, Krivit W (1980) Plasma half-life and urinary excretion of cyclophosphamide in children. Cancer Treat Rep 64(10-11):1061-6

Smith C P, Vemulakonda VM, Kiss S, Boone TB, Somogyi GT (2005) Enhanced ATP release from rat bladder urothelium during chronic bladder inflammation: effect of botulinum toxin A. Neurochem Int 47(4):291-7

Wang X, Zhang J, Xu T (2008a) Thioredoxin reductase inactivation as a pivotal mechanism of ifosfamide in cancer therapy. Eur J Pharmacol 579(1-3):66-73

Wang ZY, Wang P, Merriam FV, Bjorling DE (2008b) Lack of TRPV1 inhibits cystitis-induced increased mechanical sensitivity in mice. Pain 139(1):158-67

Xu L, Gebhart GF (2008) Characterization of mouse lumbar splanchnic and pelvic nerve urinary bladder mechanosensory afferents. J Neurophysiol 99(1):244-53

Yamada N, Hata M, Ohyama H, Yamaneg, K, Kogoe N, Nakasho K, Futani H, Okamura H, Terada N (2009) Immunotherapy with interleukin-18 in combination with preoperative chemotherapy with ifosfamide effectively inhibits postoperative progression of pulmonary metastases in a mouse osteosarcoma model. Tumour Biol 30(4):176-84

Yokoyama O, Tanaka I, Kusukawa N, Yamauchi H, Ito H, Aoki Y, Oyama N, Miwa Y, Akino H (2011) Antimuscarinics suppress adenosine triphosphate and prostaglandin E2 release from urothelium with potential improvement in detrusor overactivity in rats with cerebral infarction. J Urol 185(6):2392-7

Yoshimura N, de Groat WC (1999) Increased excitability of afferent neurons innervating rat urinary bladder after chronic bladder inflammation. J Neurosci 19(11):4644-53

Yu Y, de Groat WC (2008) Sensitization of pelvic afferent nerves in the in vitro rat urinary bladder-pelvic nerve preparation by purinergic agonists and cyclophosphamide pretreatment. Am J Physiol - Renal Physiol 294(5):F1146-56

Zagorodnyuk VP, Gibbins IL, Costa M, Brookes SJ, Gregory SJ. (2007) Properties of the major classes of mechanoreceptors in the guinea pig bladder. J Physiol 585(1):147-63 

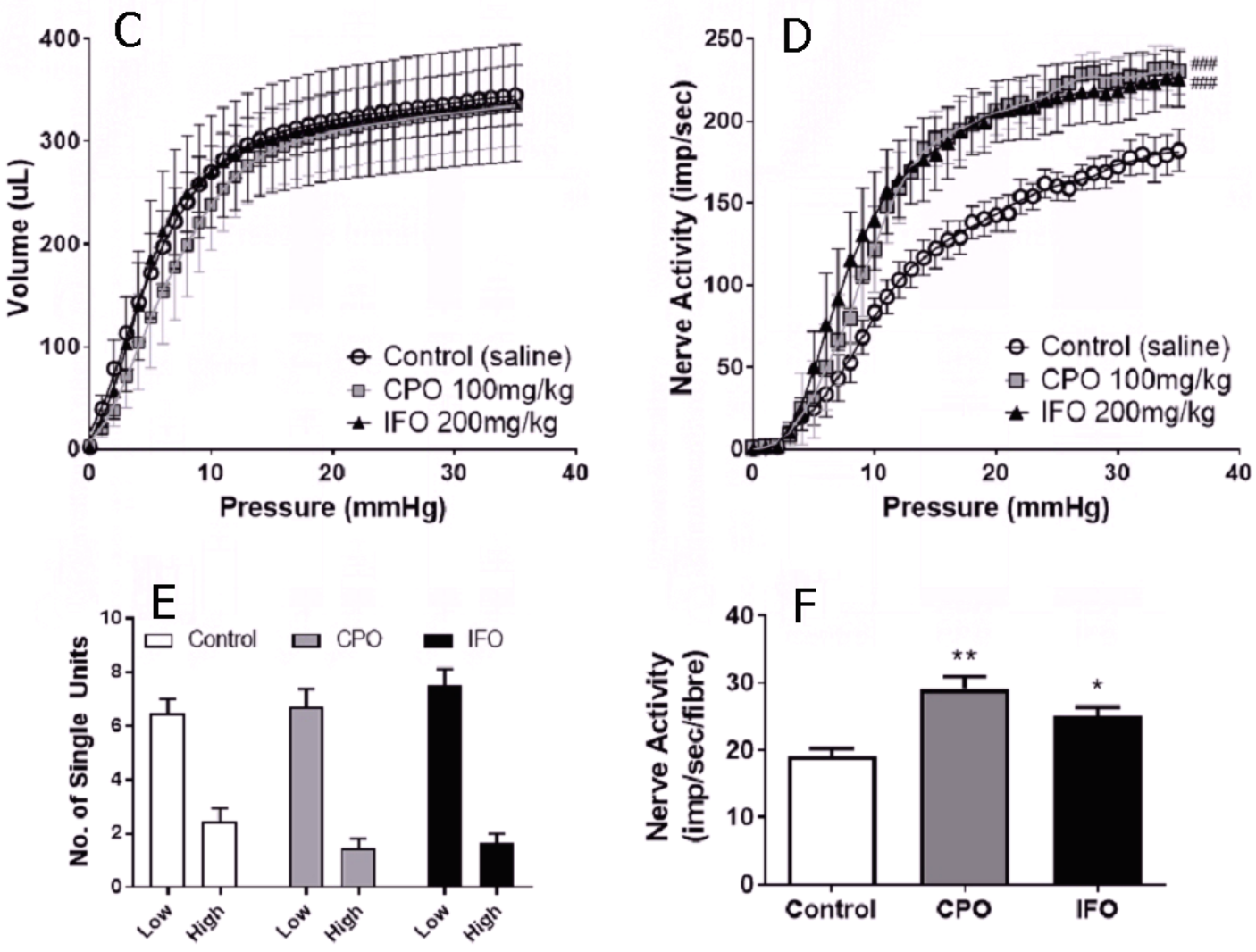

Fig 1 Experimental trace showing [A] bladder intraluminal pressure in $\mathrm{mmHg}$, and $[\mathrm{B}]$ nerve activity in impulses/sec during two repeated bladder distensions to $40 \mathrm{mmHg}$. [C] Compliance and [D] afferent nerve activity during filling of isolated bladders from mice pretreated with saline (control), CPO $(100 \mathrm{mg} / \mathrm{ml})$ or IFO $(200 \mathrm{mg} / \mathrm{ml})$. Data represented as mean \pm SEM $(n \geq 6)$. Analysed by two-way ANOVA ( ${ }^{*} p<0.05$ vs comparable control activity at individual pressure interval, \#\#p<0.001 vs whole control curve). [E] Mean ( \pm 
SEM) percentage of nerves classified as low threshold in saline, CPO or IFO treated mice $(n \geq 6)$. $[F]$ Mean ( \pm SEM) maximum nerve activity (imp/sec) per individual nerve fibre during bladder distension at $40 \mathrm{mmHg}$ in bladders from saline, CPO or IFO-treated mice. $(n \geq 6)$. Analysed by one-way ANOVA with Dunnett post test $\left({ }^{*} p<0.05,{ }^{* *} p<0.01\right.$ vs control). 

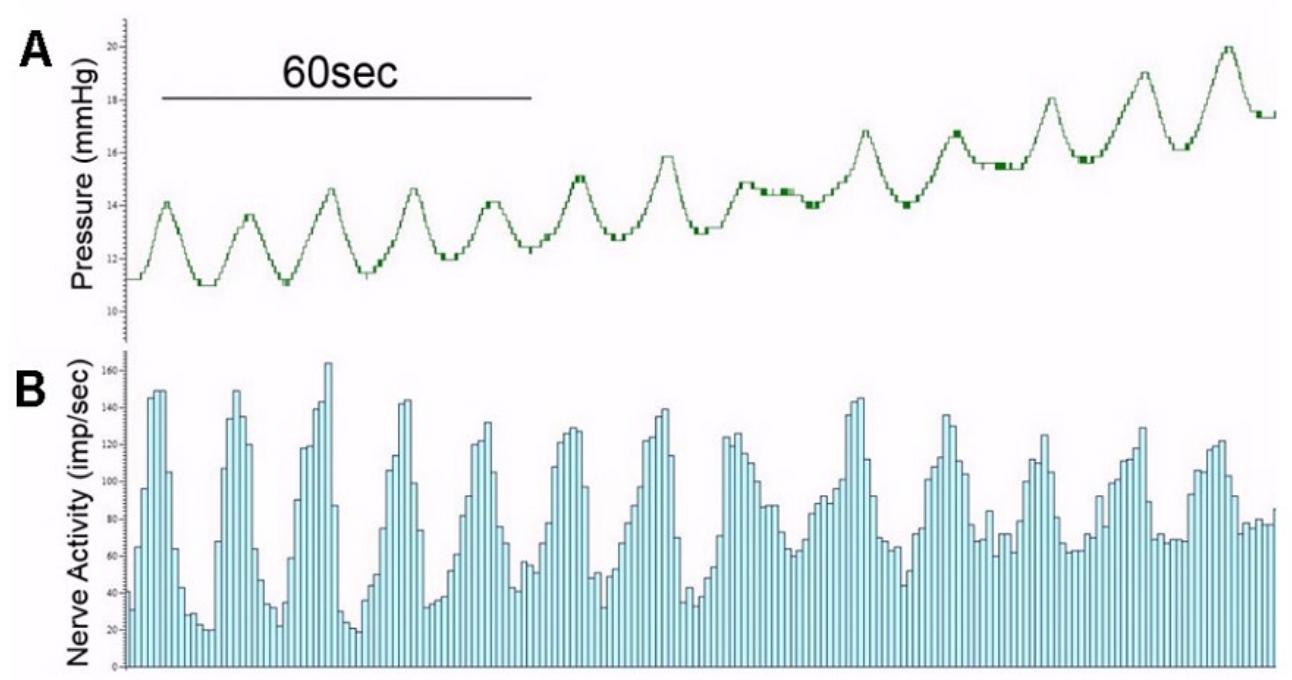

C

F requency

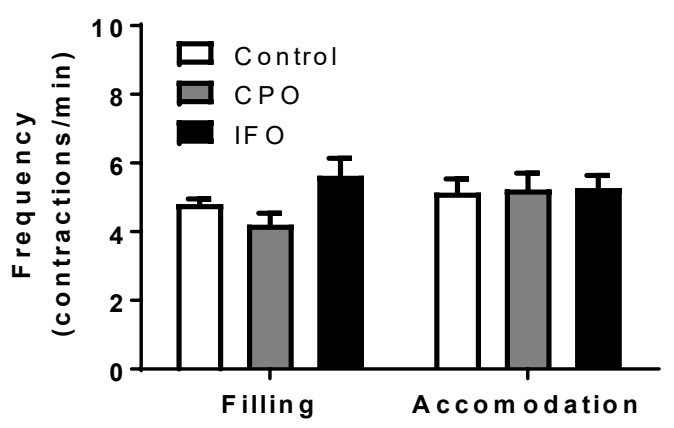

D

Amplitude

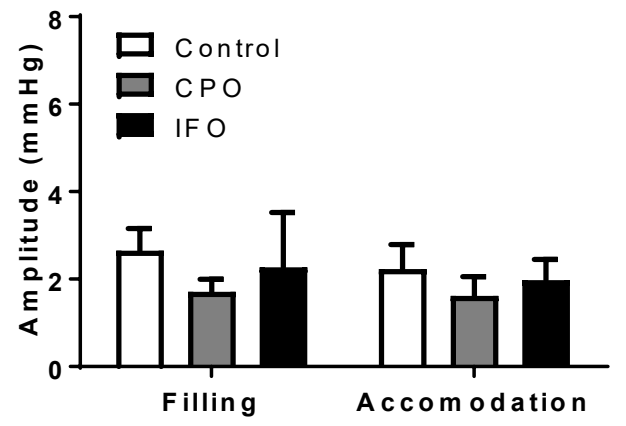

Fig 2: Figure 2: Enlarged trace showing the development of phasic contractile activity (B) during bladder filling and its association with changes in afferent nerve activity (A). This phasic contractile activity occurred in about $75 \%$ of bladders in all experimental groups. Also shown are the mean $( \pm S E M)$ frequency and amplitude values for phasic contractile activity in the three experimental groups $(n=10-11)$. 

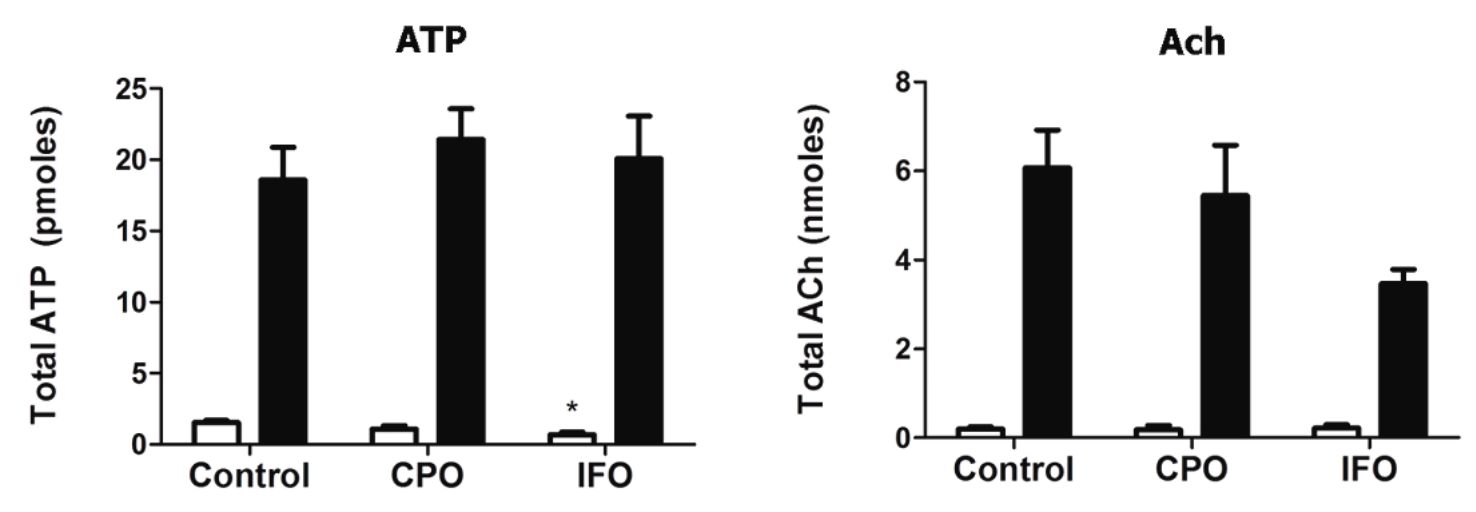

Fig 3: Mean ( \pm SEM) intraluminal (open columns) and serosal (bath) (solid columns) ATP and Ach release at maximal distension of bladders from mice treated with saline or CPO $(100 \mathrm{mg} / \mathrm{kg}) .{ }^{*} \mathrm{P}<0.05$ compared with corresponding control value, analysed using paired two-tailed Student's t-test. 

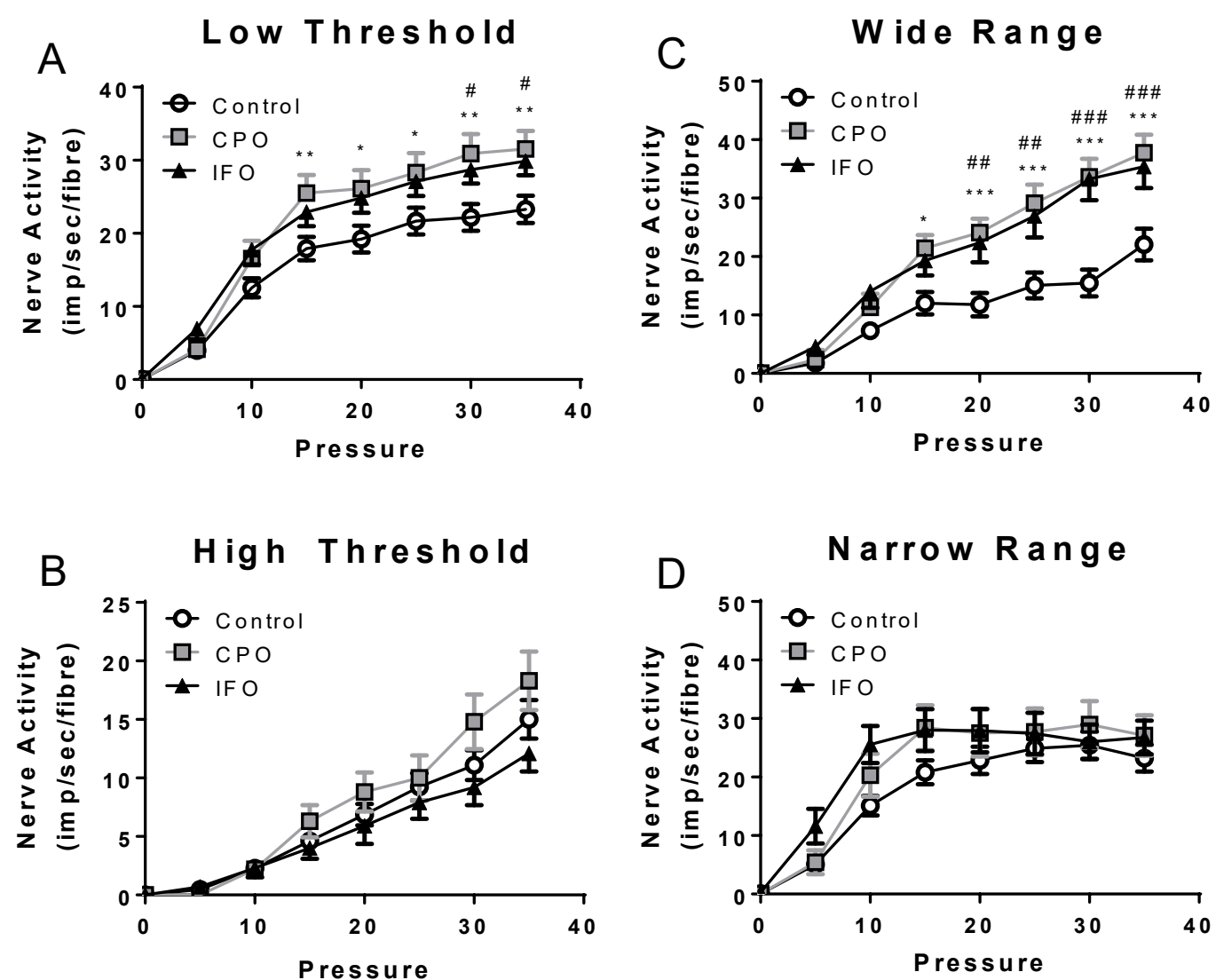

Fig 4 Afferent nerve activity of $[A]$ low threshold $(n \geq 44)$ and $[B]$ high threshold fibres $(\mathrm{n}>10)$ in bladders from control and CPO $(100 \mathrm{mg} / \mathrm{ml})$ or IFO $(200 \mathrm{mg} / \mathrm{ml})$ treated animals. Data represented as mean \pm SEM and analysed by two-way ANOVA ( ${ }^{* * *} p<0.001$ vs control). Afferent nerve activity in low threshold [C] wide dynamic range (WDR) fibres and $[D]$ narrow dynamic range (NDR) fibres $(n \geq 17)$ in control, CPO and IFO-treated animals. Data represented as mean \pm SEM and analysed by two-way ANOVA ( ${ }^{* * *} p<0.001$ vs control curve). 


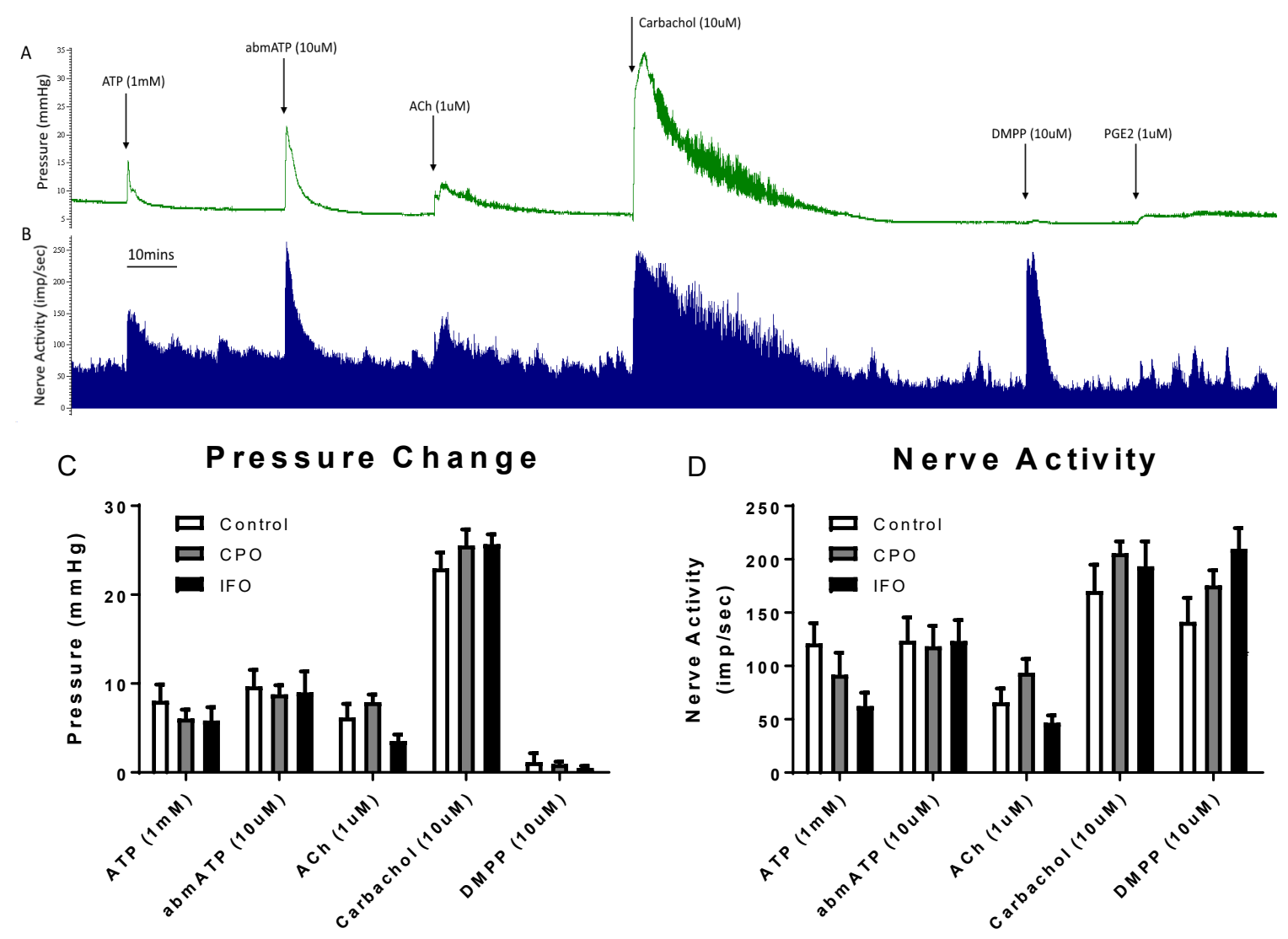

Fig 5 Experimental trace showing control pressure $[A]$ and nerve responses $[B]$ to various agonists. [C] Mean pressure responses and [D] mean nerve responses for bladders from control, CPO and IFO-treated animals to ATP (1mM), aßmATP $(10 \mu \mathrm{M})$, ACh $(1 \mu \mathrm{M})$, carbachol $(10 \mu \mathrm{M})$ and DMPP $(10 \mu \mathrm{M})$. Data represented as mean \pm SEM $(n=\geq 5)$. Responses were similar in bladders from control, CPO and IFO treated animals. Analysed by one way ANOVA with Dunnett post test $\left({ }^{*} p<0.05\right.$ vs control response for each drug). 

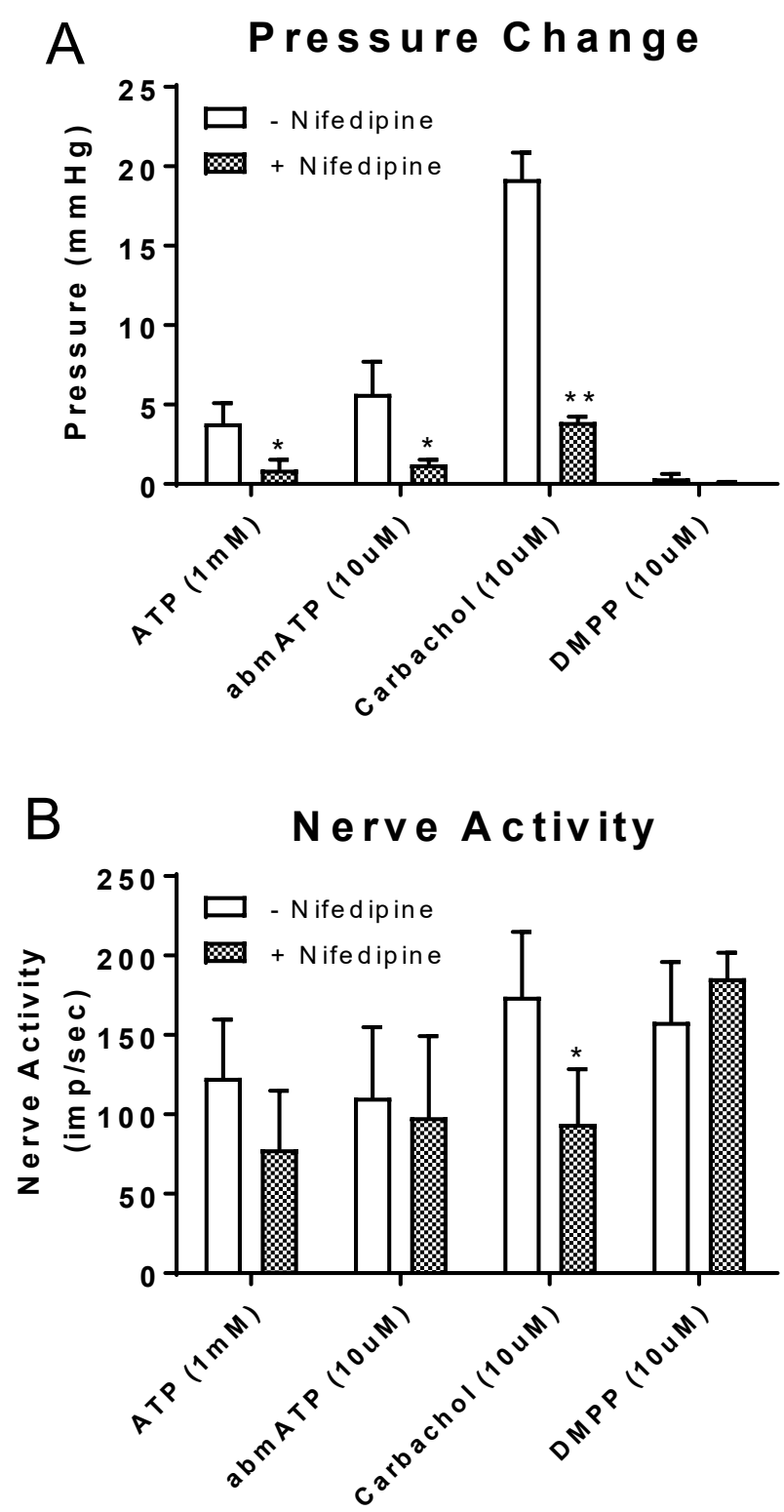

Fig 6 The effect of nifedipine $(1 \mu \mathrm{M})$ on control $[A]$ bladder pressure and $[B]$ total afferent nerve responses to ATP $(1 \mathrm{mM})$, aßmATP $(10 \mu \mathrm{M})$, carbachol $(10 \mu \mathrm{M})$ and DMPP $(10 \mu \mathrm{M})$. Data represented as mean \pm SEM $(n \geq 4)$ and analysed by paired two-tailed t-test $\left({ }^{*} p<0.05\right.$, ${ }^{* *} p<0.01$ vs absence of nifedipine) 